\title{
MAIN: The Slovak version and pilot data
}

\author{
Svetlana Kapalková \\ Comenius University
}

\author{
Monika Nemcová \\ Comenius University
}

The adaptation of the Multilingual Assessment Instrument for Narratives (LITMUS-MAIN) for use with Slovak speaking children is a vital step in the process of creating a transparent evaluation of children's narrative abilities. Since its first translation and adaptation in 2012, new pilot data from different groups of children has been collected in Slovakia. This paper describes the process of adapting the instrument to fit the Slovak language and reports on analyses of narrative production in monolingual (103 Slovak-speaking children) and bilingual (37 Slovak-English speaking) pre-school children. Within a pilot study, the story elicitation method was also compared (telling vs. retelling) within a small sample of 10 monolingual Slovak-speaking children. All results show transparent and detailed possibilities in terms of finding a meaningful evaluation that can evaluate a child's complex narrative abilities.

\section{Introduction}

A child's narrative abilities in the pre-school age are a significant predictor of their future school success. Many authors draw attention to the direct relationship between oral narratives and later literacy (McCabe, 1996; Cain, 2010; Nicolopoulou, McDowell \& Brockmeyer, 2006). A child's narrative abilities represent and reflect the summary of several of their linguistic, as well as cognitive, social, and emotional abilities. Therefore, we can assume that story telling tasks represents the most ecological way of assessing different areas of a child's language. The story structure, the level of lexical diversity used in children's language production, as well as the use of grammatical constructions expressed during storytelling, can help us to objectively define the developmental milestones of a child's language, both in terms of quantity and quality. Therefore, not having access to a structured and reliable narrative instrument poses a significant disadvantage for any pedagogical, psychological, or speech-language practice. In Slovakia, 
child specialists have usually asked children to recount a personal story, to retell a story that has previously been told by adults, or to speak about events from their daily life. All these types of narratives have many limitations, such as the lack of an objective and transparent process for assessing the child's narrative ability. The fact that the children's stories differ in topic and length, and are influenced by the cultural background of their family can also negatively influence the children's ability to produce a cohesive story. Additionally, due to these factors, it becomes much more difficult to compare their individual narrative abilities. As a result of designating objective and structured ways in which to ensure the same assessment criteria for all, the Multilingual Assessment Instrument for Narratives (LITMUS-MAIN, hereafter MAIN; Gagatina et al., 2012, 2015) was developed during the research project COST Action IS0804 Language Impairment in a Multilingual Society: Linguistic Patterns and the Road to Assessment by one the working group on discourse. MAIN has since been revised (Gagarina et al., 2019). Svetlana Kapalková and Daniela Slančová were members and representatives for Slovakia in the COST project, as well as partial members of the working group on discourse during the adapting process of the instrument. Here, we present the adaptation of MAIN to Slovak, based on the revised MAIN (Gagarina et al., 2019), and report results for the studies that have used the Slovak MAIN since 2012, including recent pilot studies.

\section{A brief description of the Slovak language}

Slovak is the mother tongue of approximately 4.5 million people in Slovakia. Additionally, about 2.8 million people of Slovak origin live outside of Slovakia (Ondrejovič, 2009). With respect to language typology, Slovak is a West-Slavic language. It has a rich morphology, is heavily reliant on inflections, and has a relatively free word order. These features are all in stark contrast to English with its sparse morphology and reliance on function words within a stricter word order. Slovak is a pro-drop language, and pronominal subjects are usually omitted unless particular emphasis is required (Kesselová \& Slančová, 2010).

\section{$3 \quad$ Adapting MAIN to Slovak}

MAIN is quite complex instrument. It allows for the evaluation of both narrative comprehension and production. The assessment of narrative production focuses on two main domains: macrostructure and microstructure. The theoretical framework for macrostructure is based on the story grammar model, which is seen as the universal knowledge about storytelling and is defined by story components, characters, and sequence of events (Stein \& Glenn, 1979). All of these facts have motivated us to adapt the MAIN in a way which would allow specialists in Slovakia to employ it also.

The first step in the process of adapting MAIN to Slovak, the translation of the story scripts and scoring protocols by Svetlana Kapalková, took place during the COST project. These translations were later adapted to match the revised English version (Gagarina et al., 
2019). During the translation process, Daniela Slančová, as a linguist, checked the meaning, as well as the appropriateness of the language used.

The first topic that was discussed at this stage of the process concerned the story characters names. In the English version, the gender of the animals (the cat or the fox) does not need to be specified, and can, therefore, be referred to with the same words regardless of their actual gender. Due to the nature of the Slovak language, gender has to be specified, and we have, therefore, decided to allow the use of both gender forms of the words in the Slovak version (e.g. for the cat: mačka 'female cat' and kocúr 'male cat'). However, in the Cat story we decided to name the cat in the feminine form (mačka) since that Slovak children much more often identify the character as feminine. In contrast, in the Baby Birds story, we used the masculine form of word cat (kocúr). (Here, children used both forms equally.) Additionally, in the Baby Goats story, based on the children's answers we decided to use the masculine form of the word fox (lišiak). A similar situation appeared with naming the bird characters. In Slovak, distinctions are often made based on the size of objects and characters, most notably through the use of the diminutive form, e.g. vták 'bird' and vtáčik 'little bird'.) In this case, it was culturally more appropriate to use the diminutive word for bird (vtáčik) in the Baby Birds story. In contrast, in the Baby Goats story, we used the neutral word for bird (vták), since this was more suitable based on the picture of the bird and the situation.

When the narrative macrostructure of the stories was controlled, we realized the importance of expressing internal terms as initiating events and reactions. We also carefully checked all relevant adjectives, adverbs, and verbs when finding their closest meaning parallels within the Slovak language. In microstructure, we used the same number of coordinating and subordinating constructions, and the number of direct speech sentences as in the English version.

In the end, the number of words used in the Slovak stories is approximately 40 words less than in English. One of the reasons for this difference is the absence of the (in)definite articles in Slovak. Additionally, since Slovak is a pro-drop language, an overt pronoun does not have to be used. However, the all four stories have a similar number of words in Slovak (Baby Birds: 139, Baby Goats: 143, Cat: 147, Dog: 146 words).

Next, the Slovak version of MAIN was translated back to the English version by Martin Kubán̆, a professional translator. We then checked and compared the scripts to check for discrepancies. No major discrepancies were found.

Finally, six students of speech-language therapy (Lenka Marková, Alexandra Pyšná, Luudmila Mičianová, Kristína Schweighoferová, Monika Schieberová, Klára Krokusová and Monika Nemcová), who were native speakers of Slovak checked the text of Slovak version carefully. All of these students have also administered the working version of Slovak MAIN to collect the first Slovak pilot data. Based on the feedback from the children's data, we then finalized the Slovak version. Below, we describe our preliminary results from three studies using the Slovak MAIN. 


\section{$4 \quad$ Using the Slovak MAIN in research}

\subsection{Study 1: Monolingual Slovak-speaking pre-school children}

In Study 1, we examined to what extent monolingual typically-developing Slovak-speaking pre-school children expressed story structure in their narratives. Our sample consisted of 102 children. We asked whether there were significant differences between 3-, 4-, and 5-year-olds in the number of macrostructural components they expressed in their narratives. Table 1 gives an overview of the three groups.

Table 1: Age description of monolingual pre-school children.

\begin{tabular}{llllll}
\hline Age group & $\mathbf{N}$ & Mean & SD & Min & Max \\
\hline 3-year-olds & 18 & 42.72 & 4.39 & 37 & 48 \\
4-year-olds & 33 & 56.52 & 2.69 & 51 & 60 \\
5-years-olds & 52 & 67.94 & 4.08 & 61 & 75 \\
\hline
\end{tabular}

All children were asked to tell one of the MAIN stories (Cat, Dog, Baby Birds, Baby Goats) and afterwards answered the comprehension questions. The procedure and method of counterbalancing from Gagarina et al. (2012) was followed, and the scoring of the story structure was done according to the MAIN scoring protocol. For expressing the different components of the story structure (setting, internal states as the initiating event, goal, attempt, outcome, internal state as reaction), the maximum score was 17 points. The results for the three age groups are given in Table 2.

Table 2: Story structure scores, one MAIN story, Slovak monolinguals pre-school children.

\begin{tabular}{lllllll}
\hline Age Group & N & Median & Mean & SD & Min & Max \\
\hline 3-year-olds & 18 & 3 & 3.33 & 1.57 & 1 & 6 \\
4-year-olds & 33 & 5 & 4.61 & 1.77 & 1 & 9 \\
5-year-olds & 52 & 5.5 & 5.62 & 1.52 & 3 & 9 \\
\hline
\end{tabular}

The distribution of the story structure scores were significantly non-normal for the 4- and 5year-olds (3-year-olds, $\mathrm{D}(18)=0.915, \mathrm{p}>.05$; 4-year-olds, $\mathrm{D}(33)=0.164, \mathrm{p}<.05 ; 5$-year-old $\mathrm{D}(52)=0.170, \mathrm{p}<.05)$. Consequently, we compared the three age groups using the nonparametric Kruskal-Wallis test. The number of macrostructure components expressed differed significantly between the age groups $(\mathrm{H}(3)=20.76$, $\mathrm{p}<0.001)$. Man-Whitney tests (Bonferronicorrected) were used to follow up these findings. The youngest children, the 3 -year-olds, 
expressed fewer components than the 4-year-olds $(U=177, \mathrm{r}=-0.336)$, and the 4-year-olds expressed fewer components than the 5-year-olds $(U=592, r=-.266)$.

\subsection{Study 2: A comparison of elicitation methods (telling vs. retelling)}

Since MAIN offers different methods of eliciting narratives, telling, retelling, and model story (Gagarina et al. 2012; 2019), we decided to compare two of them (telling and retelling) using a small sample of 10 typically-developing Slovak-speaking children (Pyšná \& Kapalková, 2012). The mean age of the children was 82.3 months (range 74-92, SD 5.7). The children were asked to tell and retell one out of two MAIN stories which were assigned randomly (Cat and Baby Birds). The order of the elicitation modes was counter-balanced too; half of the children first told the story while the rest of the children first retold the story. Due to the small sample, we analyzed the results as descriptive statistics and qualitatively for both macro- and microstructure.

On average, children expressed fewer macrostructural components in their tellings (6.3 components, SD 2.21), compared to in their retellings (8.4 components, SD 2.80). However, the results for the microstructure are less clear. For microstructure, we compared the following: total number of spoken words, lexical diversity (TTR), total number of utterances, and the number of clauses. The overview is offered in Table 3.

Table 3: Microstructure measures for the telling and retelling story respectively by the same children.

\begin{tabular}{lllll}
\hline & $\begin{array}{l}\text { Mean } \\
\text { Tell/Retelling }\end{array}$ & $\begin{array}{l}\text { SD } \\
\text { Tell/Retelling }\end{array}$ & $\begin{array}{l}\text { Min } \\
\text { Tell/Retelling }\end{array}$ & $\begin{array}{l}\text { Max } \\
\text { Tell/Retelling }\end{array}$ \\
\hline $\begin{array}{l}\text { Total number of words } \\
\text { (TNW) }\end{array}$ & $63.8 / 58.7$ & $31.25 / 17.53$ & $26 / 39$ & $135 / 88$ \\
$\begin{array}{l}\text { Total number of } \\
\text { utterances (TNU) }\end{array}$ & $8.2 / 7.5$ & $2.39 / 2.17$ & $5 / 5$ & $12 / 11$ \\
$\begin{array}{l}\text { Type-token ratio } \\
\text { (TTR) }\end{array}$ & $55,7 \% / 64 \%$ & $13.55 / 8.11$ & $41 \% / 53 \%$ & $85 \% / 83 \%$ \\
\hline
\end{tabular}

Based on the pilot data presented above, the shared knowledge between the administrator and the child during the retelling elicitation (where both of them look at the story pictures), influences the microstructure. Children tended to express less words during the retelling story, in contrast to a higher number of words expressing macrostructure components in the same process. 


\subsection{Study 3: Bilingual Slovak-speaking pre-school children}

A central feature of the MAIN instrument is the possibility to assess the narrative skills of bilingual children in both languages using the same instrument. Based on the suggestion that macrostructure performance is mainly dependent on cognitive patterns and less dependent on language skills, we analyzed the same macrostructure components in both L1 and L2. In Kapalková, Polišenská, Marková and Fenton (2016), we analyzed narratives from 38 successive Slovak-English bilinguals, with Slovak as their L1, and English as their school language (L2). In each language, the children told one story and retold another story. In total, the maximum was 34 points for expressing the macrostructural components in each language. We hypothesized that the production of macrostructural components in L1 and L2 would not differ significantly in children with a minimum of 12 months of intensive exposure to English as an L2. The hypothesis was addressed by a comparison of macrostructure production scores across two languages (L1 vs. L2). A paired-samples t-test with a number of macrostructural components as the dependent variable revealed a significant effect on language, $\mathrm{t}(38)=.34, \mathrm{p}$ $<.001$, with the children achieving higher scores in their $\mathrm{L} 1(\mathrm{M}=15.49, \mathrm{SD}=2.69)$ compared to their $\mathrm{L} 2(\mathrm{M}=13.39, \mathrm{SD}=3.38)$. The hypothesis was thus not proven. However, the order of acquiring the macrostructural components seems to be the same in both languages. In the beginning of the development of narrative skills, we see an expression of the Attempt and the Outcome, as they are the most uncomplicated story components in both languages. The most demanding expression is the Internal States as Reaction component. The same trajectory was described by Samko \& Kapalková (2014) in their case study of one successive bilingual preschool Roma-Slovak-speaking child with Slovak as L2.

\section{$5 \quad$ Conclusion and future steps}

The different conditions under which the Slovak version of the MAIN instrument was piloted proves its appropriateness and attractiveness for the evaluation of a child's narrative language in Slovakia. It is also very useful that is can be used with different elicitation methods, combined with comprehension questions. Its quick administration offers a lot of linguistic information about a child, which is why it is necessary not only as a research tool but also as a diagnostic instrument for describing children who are at risk for language delay or developmental language disorder during the preschool age. It would be very important, as a next step, to have more clinical studies comparing typical children and children with developmental language disorders to prove the sensitivity of MAIN. We hope to be able to begin collecting normative data in Slovakia soon, after which we can offer some referential data to specialists who work with children. A very important next step will be to describe all the psychometric features of the tool, its validity, reliability, sensitivity, and what is necessary for its clinical use. 


\section{References}

Cain, K. (2010). Reading development and difficulties. Chichester, UK: Blackwell Publishing.

Gagarina, N., Klop, D., Kunnari, S., Tantele, K., Välimaa, T., Balčiūnienė, I., Bohnacker, U., \& Walters, J. (2012). MAIN: Multilingual Assessment Instrument for Narratives. ZAS Papers in Linguistics, 56.

Gagarina, N., Klop, D., Kunnari, S., Tantele, K., Välimaa, T., Balčiūnienė, I., Bohnacker, U., \& Walters, J. (2015). Assessment of Narrative Abilities in Bilingual Children. In S. Armon-Lotem, J. de Jong, \& N. Meir (Eds.), Assessing multilingual children disentangling bilingualism from language impairment (pp. 243-269). Bristol: Multilingual Matters.

Gagarina, N., Klop, D., Kunnari, S., Tantele, K., Välimaa, T., Bohnacker, U. \& Walters, J. (2019). MAIN: Multilingual Assessment Instrument for Narratives - Revised. ZAS Papers in Linguistics, 63.

Kapalková, S., Polišenská, K., Marková, L., \& Fenton, J. (2016). Narrative abilities in early successive SlovakEnglish children a cross-language comparison. Applied Psycholinguistics, 37(1), 145-164.

Kesselová, J., \& Slančová, D. (2010). Slovak. Revue Belge de Philologie et d'Histoire, 88(3), 873-896.

Krajčírová, K. (2016). The analysis of macrostructure and microstructure in the children narration in first and second grade. (Unpublished master's thesis). Faculty of Education Comenius University, Bratislava, Slovakia.

McGabe, A. (1996). Evaluating narrative discourse skills. In K. Cole, P. Dale \& D. Thal (Eds.), Assessment of Communication and Language (pp. 121-142). Baltimore, MD: Paul H. Brooks.

Nicolopoulou, A., McDowell, J., \& Brockmeyer, C. (2006). Narrative play and emergent literacy: Storytelling and story-acting meet journal writing. In D. Singer, R. Golinkoff \& K. Hirsh-Pasek (Eds.), Play = Learning (pp. 124-144). New York, NY: Oxford University Press.

Ondrejovič, S. (2009). The Slovak Language, Languages in Slovakia. Bratislava: Ministry of Foreign Affairs of the Slovak Republic. Public Diplomacy Department.

Pyšná, A., \& Kapalková, S. (2012). Porovnanie hodnotenia naratívnych schopností slovensky hovoriacich detí vo veku 6-7 rokov metódou rozprávania a prerozprávania. Jazyk a kultúra, 3(10), 1-13.

Samko, M., \& Kapalková, S. (2014). Analýza naratívnej schopnosti rómskeho diet’at’a v rómčine a slovenčine. Psychológia a patopsychológia diet'at'a, 48(3-4), 372-384.

Stein, N. L., \& Glenn, C. (1979). An analysis of story comprehension in elementary school children. In R. O. Freedle (Ed.), New directions in discourse processing (pp. 53-120). Norwood, NJ: Ablex. 